\title{
The Influence of Technological Factors on the Strength of Adhesive Joints of Steel Sheets
}

\author{
Elżbieta Doluk ${ }^{1 *}$, Anna Rudawska' ${ }^{1}$ Valentina Brunella² \\ 1 Lublin University of Technology, Faculty of Mechanical Engineering, Nadbystrzycka 36, 20-618 Lublin, Poland \\ 2 University of Turin, Department of Chemistry, Via P. Giuria 7, Turin, Italy \\ * Coresponding author's e-mail: e.doluk@pollub.pl
}

\begin{abstract}
The paper evaluates the effect of the surface treatment on the strength of the single-lap adhesive joints made of the C45 steel. The samples were joined using an adhesive composition consisting of Epidian 57 epoxy resin and PAC curing agent. The study also used Greinplast mosaic plaster with a grain size of $1.0-1.6 \mathrm{~mm}$ as coating. The experiment was carried out for 3 variants of joints: sheet/sheet, sheet+plaster/sheet + plaster, sheet/sheet + plaster. Each variant was divided into 3 methods of surface treatment. The strength tests were carried out on the Zwick/Roell Z150 testing machine. The roughness parameters of the surface's samples were measured using a HOMMEL TESTER T1000 profilometer.
\end{abstract}

Keywords: adhesive joint, shear strength, surface roughness

\section{INTRODUCTION}

The constant development of materials engineering as well as the use of newer technological and construction solutions necessitate improving the techniques of joining materials. One of the methods of making joints, which plays an increasingly important role in many industries, is bonding [1, 2-4]. An example pertaining to the use of this type of joints is the increasing application of adhesive joints in the aviation industry [3]. The interest in the process is mainly related to the need to minimize the mass and number of joints in aircraft constructions [4-6]. Adhesive bonding has also found wide application in the automotive industry, in the production of passenger cars or buses $[2,7]$.

Bonding is a process consisting of several stages. A properly carried out process of joining materials with adhesive requires a very well thought-out selection of the activities and factors accompanying the process $[2,8,9]$.

One of the most important stages of bonding is the treatment of the surface of the adherends, ensuring the desired strength of the joint $[10,11]$. The process of surface treatment involves the removal of impurities and the appropriate development of the joined surfaces. The choice of surface treatment depends on the type of materials to be joined, employed adhesive or the intended use [12-15]. The strength of an adhesive joint depends on many factors. The main technological aspects affecting the strength of the adhesive joint include the length of the overlap, the thickness of the adhesive joint, the thickness of the adherends, the size of the spew fillet, the stiffness of the adhesive and the stiffness of the joined materials $[9,16-19]$. The aim of the experiment was to determine the impact of technological factors on the strength of single-lap adhesive joints made in 3 different variants using a $\mathrm{C} 45$ steel sheet.

\section{EXPERIMENT}

The subject of the research involved single-lap adhesive joints made of the $\mathrm{C} 45$ steel. In the study, Greinplast mosaic plaster with a grain thickness 
of 1.0-1.6 mm was used as an additional factor influencing the strength of the adhesive joint. The adhesive joints were made in three variants: variant I: sheet/sheet, variant II: sheet+plaster/ sheet+plaster, variant III: sheet/sheet+plaster. The shapes and dimensions of the samples after the bonding process are shown in Figure 1.

The dimensions of the samples were as follows:

- $1=100 \mathrm{~mm}-$ length of the sample,

- $b=25 \mathrm{~mm}-$ sheet width,

- $\mathrm{g}=1 \mathrm{~mm}$ - sheet thickness,

- $1_{z}=20 \mathrm{~mm}-$ the length of the tab,

- $\mathrm{g}_{\mathrm{t}}=2.66-3.74 \mathrm{~mm}-$ thickness of the sheet with plaster.

The appearance of the samples covered with mosaic plaster and adhesive joints with the use of plaster are presented in Figure 2.

The samples of adherend for each variant of bonded joints were subjected to 3 methods of surface treatment: mechanical treatment with the P120 grain size abrasive paper and degreasing, mechanical treatment with the P800 grain size abrasive paper and degreasing or degreasing using extraction gasoline. After completing the above-mentioned steps, Greinplast mosaic plaster was applied to some of the samples (variant II and III). Table 1 presents the methods of surface treatment and determination of the samples in each variant.

The preparation of the samples for the bonding process and the application of the plaster were carried out at $29 \pm 2^{\circ} \mathrm{C}$ with an air humidity of
$38 \pm 2{ }^{\circ} \mathrm{C}$. The time of seasoning the samples with plaster was 48 days.

An adhesive composition formed by mixing Epidian 57 epoxy resin and PAC curing agent in a weight ratio of 1:1 was used for joining the samples. The adhesive was applied to both surfaces with a thin layer. The process of making joints was carried out at $30^{\circ} \mathrm{C}$ and humidity was $30 \%$. The adhesive joint was loaded for 2 days with $2 \mathrm{~kg}$ weights and then cured for 46 days without load.

The strength tests were carried out on a Zwick / Roell Z150 testing machine in accordance with the recommendations of the standard [20].

The surface roughness measurements were made for 3 methods of the sample surface treatment: P120 abrasive paper, P800 abrasive paper or surface degreasing only. The surface roughness parameters such as Ra, Rz, Rsm were measured using a HOMMEL TESTER T1000 profilometer. The measuring procedure involved performing a series of 10 measurements according to the standard [21].

\section{ANALYSIS AND MEASUREMENT}

\section{Surface roughness}

The surface roughness test was performed for 3 samples for each method: mechanical treatment with the P120 abrasive paper, mechanical treatment with the P800 abrasive paper and on the samples that have not been subjected to any a)

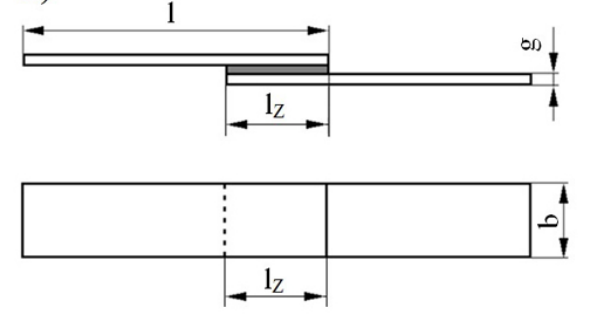

b)

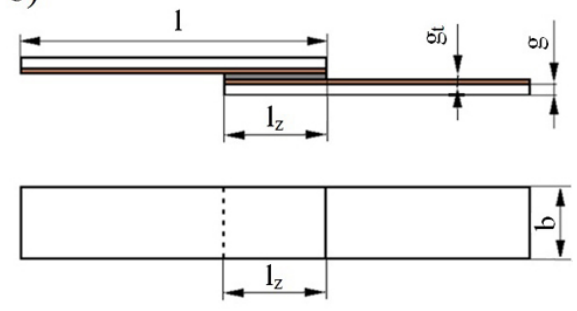

c)
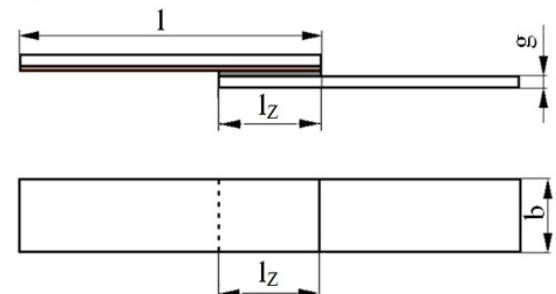

Fig. 1. The shape and dimensions of the adhesive joint samples after the bonding process: a) variant I, b) variant II, c) variant III 
a)

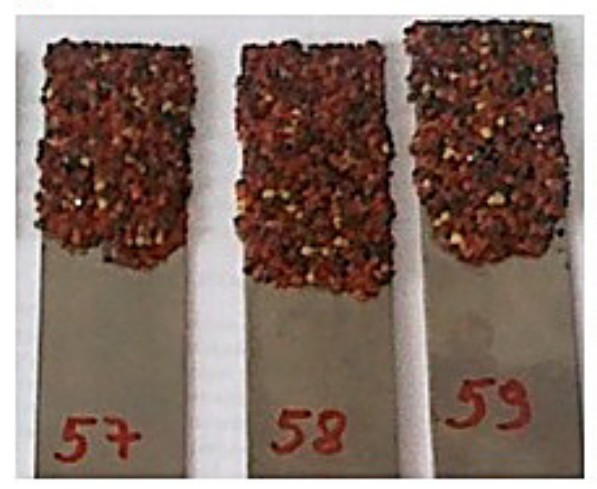

b)

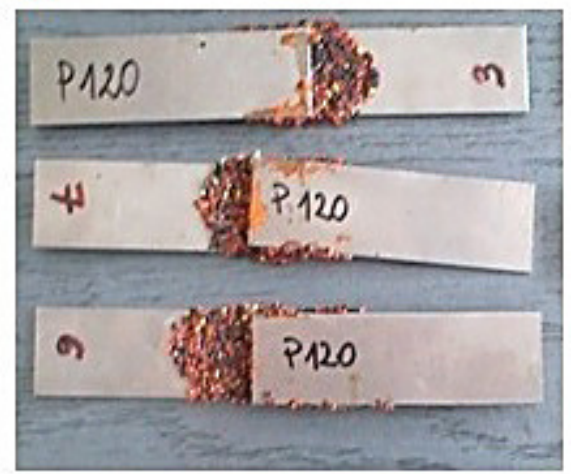

Fig. 2. Application of mosaic plaster in the experiment:

a) samples covered with a plaster, b) adhesive joints using a plaster

treatment. Three measurements were conducted for each sample. Fig. 3 presents the surface roughness parameters depending on the method of the sample treatment. The presented values of surface roughness parameters are the average value obtained from 9 measurements.

The lowest average Ra parameter value was obtained for the samples processed with the P800 abrasive paper $(\mathrm{Ra}=1.65 \mu \mathrm{m})$ and the highest for the samples processed with the $\mathrm{P} 120$ abrasive paper $(\mathrm{Ra}=1.7 \mu \mathrm{m})$. The lowest average roughness values for the $\mathrm{Rz}$ and $\mathrm{Rmax}$ parameters were observed for the samples prepared with the P800 grain size abrasive paper $(\mathrm{Rz}=9.92 \mu \mathrm{m}$, $\operatorname{Rmax}=11.91 \mu \mathrm{m})$ and the highest with P120 abrasive paper $(\mathrm{Rz}=11.91 \mu \mathrm{m}, \mathrm{Rmax}=14.33 \mu \mathrm{m})$. For all measured surface roughness parameters, the treatment with the P120 abrasive paper resulted in obtaining higher values compared to the surfaces without treatment. The use of P800 abrasive paper for all tests allowed receiving lower values of surface roughness than in the case without any mechanical treatment.

The average $\mathrm{Ra}$ value gained during the P120 paper treatment was about $4 \%$ higher than the average value of this parameter received for the untreated surface. The treatment with the P800 abrasive paper allowed obtaining less than $1 \%$ lower $\mathrm{Ra}$ values compared to the Ra values achieved for the variant without the use of abrasive paper.

The difference between the average Rz value obtained using the P120 abrasive paper and without treatment was about $97 \%$, while between P800 and without treatment, it amounted to $9 \%$. The average Rmax obtained after the P120 treatment was about $1 \%$ higher than the average value of this parameter achieved without treatment. The value of the Rmax parameter obtained after the treatment with the P800 abrasive paper was about $15 \%$ lower than the Rmax measured on the surfaces of the untreated samples.

All maximum values of the measured roughness parameters were achieved for the samples prepared with the P120 abrasive paper and the lowest with the P800 abrasive paper. The difference between the highest and lowest average value of the parameters were: $\mathrm{Ra}-4 \%, \mathrm{Rz}-17 \%$, $\mathrm{R} \max -17 \%$.

Table 1. Methods of the surface treatment

\begin{tabular}{|c|c|c|}
\hline Variant & Method of the surface treatment before mosaic plaster coating & Sample designation \\
\hline \multirow{3}{*}{ I } & Mechanical treatment with P120 abrasive paper and degreasing & $\mathrm{P} 120$ \\
\hline & Mechanical treatment with P800 abrasive paper and degreasing & $\mathrm{P} 800_{1}$ \\
\hline & Degreasing & $D_{1}$ \\
\hline \multirow{3}{*}{ II } & Mechanical treatment with $\mathrm{P} 120$ abrasive paper and degreasing & $\mathrm{P} 120_{\|}$ \\
\hline & Mechanical treatment with P800 abrasive paper and degreasing & P800 ॥ \\
\hline & Degreasing & $\mathrm{D}_{\|}$ \\
\hline \multirow{3}{*}{ III } & Mechanical treatment with $\mathrm{P} 120$ abrasive paper and degreasing & $\mathrm{P} 120_{\text {III }}$ \\
\hline & Mechanical treatment with P800 abrasive paper and degreasing & $\mathrm{P}^{2} 80_{111}$ \\
\hline & Degreasing & $\mathrm{D}_{\mathrm{II}}$ \\
\hline
\end{tabular}




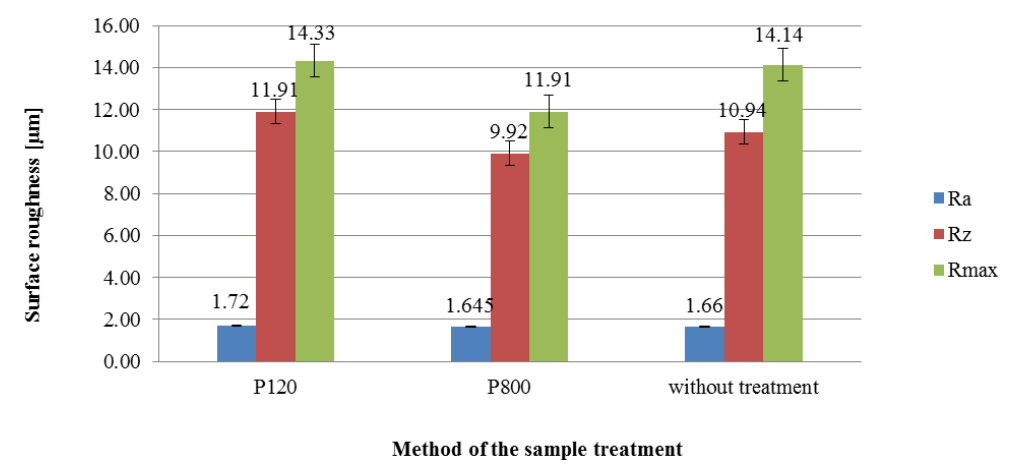

Fig. 3. Results of surface roughness parameters

\section{Strength of adhesive joints}

The shear strength results of the single-lap adhesive joints are shown in Figure 4.

While analyzing Figure 4, it can be observed that the highest average values of the shear strength for all surface treatments were obtained for variant I. The lowest average values of the strength were observed for variant II. The highest value of shear strength was obtained for machining with the P800 abrasive paper and degreasing (9.87 MPa) and the lowest with use only degreasing $(0.33 \mathrm{MPa})$. The difference between the highest and lowest shear strength was about $97 \%$.

The maximum average value of the shear strength for variant I was obtained for the treatment with the P800 abrasive paper and degreasing $(9.87 \mathrm{MPa})$, while the lowest was gained for the samples without abrasive the paper treatment $(6.87 \mathrm{MPa})$. The difference between the extremes was $3 \mathrm{MPa}$, i.e. $30 \%$. For variant II, the maximum value value of shear strength was observed for the surfaces prepared with the P120 abrasive paper and degreasing $(0.52 \mathrm{MPa})$, the lowest for samples prepared only by degreasing $(0.33 \mathrm{MPa})$. The difference between the values was $0.19 \mathrm{MPa}$, i.e. $37 \%$. The maximum value of shear strength for variant III was achieved for the samples the surfaces of which were only degreased (1.26 MPa) and the smallest for the surfaces prepared with the P800 abrasive paper and degreasing $(0.79 \mathrm{MPa})$. The difference between extremes was $0.47 \mathrm{MPa}$, i.e. $37 \%$.

The maximum differences in the shear strength achieved depending on the method of the sample surface treatment were: $7.13 \mathrm{MPa}$, i.e. 93\% with the P120 abrasive paper and degreasing, $9.48 \mathrm{MPa}$, i.e. $96 \%$ with the $\mathrm{P} 800$ abrasive paper and degreasing, and $6.54 \mathrm{MPa}$, i.e. $95 \%$ with degreasing only.

\section{Statistical analysis}

In order to investigate the effect of the surface treatment on the strength of the single-lap joints for the considered variants, a statistical analysis was performed using the STATISTICA 13.3 software package. It was used to calculate the parameters of descriptive statistics for each of the variants. Statistical tests such as: Shapiro Wilk test, Fisher-Snedecor test, Student t-test, and Cochran-Cox test, were performed. All tests were

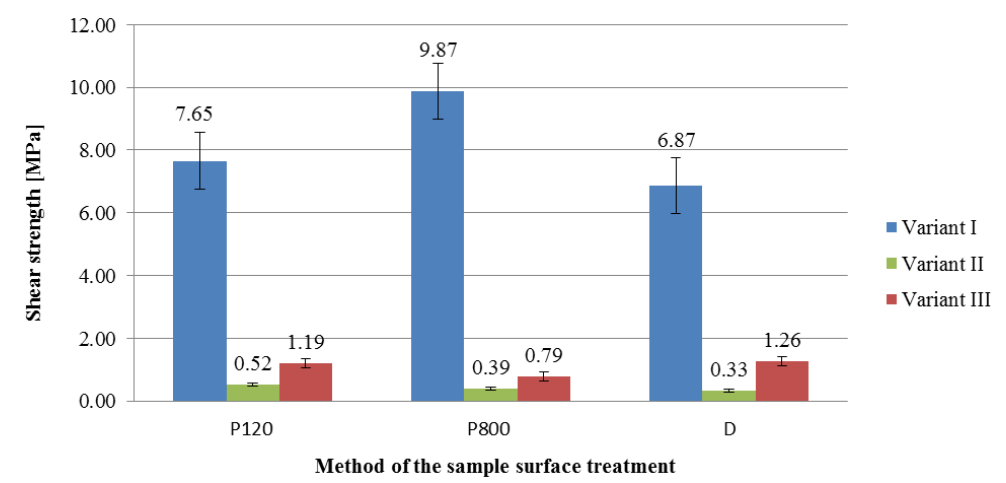

Fig. 4. Average values of the shear strength of the single-lap adhesive joints for the considered variants 
carried out at the significance level of $\alpha=0.05$. Table 2 presents the hypotheses that were adopted for each of the tests mentioned above.

The statistical analysis was started from the study of the normality of the distribution of the results. For this purpose, the Shapiro-Wilk test was carried out. On the basis of the data summarized in Table 3, it can be concluded that all obtained strength results are normally distributed.

The visual interpretation of the test of normality was presented by histograms of normality in Figures 5-7.

In order to determine the occurrence of the statistically significant differences in the strength values obtained depending on the method of surface treatment, the Fisher-Snedecor test, t-Student test and Cochran-Cox test were performed. The effects of the above-mentioned tests were collected in Tables 4-6.

On the basis of Table 4, it was found that among all performed comparisons of the shear joint strength, 5 of them did not show statistically significant differences in terms of precision at the assumed level of significance. In connection with the above, these results were subjected to the $\mathrm{t}$-Student test. The results of this test are listed in Table 5. The Cochran-Cox test (Table 6) was performed for the compared samples, which showed statistically significant differences in terms of precision.

On the basis of the developed tests, it was found that between the P800 $-\mathrm{D}_{\mathrm{I}}, \mathrm{P} 120_{\mathrm{I}} \mathrm{P} 800_{\mathrm{I}}$ and $\mathrm{P} 120_{\mathrm{III}}-\mathrm{D}_{\mathrm{III}}$ results, there are statistically significant differences in terms of accuracy. The other compared methods of surface preparation gave statistically similar effects.

\section{CONCLUSIONS}

The aim of the experiment was to determine the effect of the surface treatment method and the variant of the joint performance on the strength of the single-lap adhesive joints. Three methods of surface treatment for each of 3 adhesive joints were examined. In order to estimate the occurrence of the strength differences between the considered adhesive joints, the parameters of

Table 2. Hypotheses accepted for statistical analysis

\begin{tabular}{|c|c|}
\hline Test & Hypothesis \\
\hline \multirow{2}{*}{ Shapiro-Wilk } & $\mathrm{H}_{\mathrm{o}}-$ data are normally distributed \\
\hline & $\mathrm{H}_{1}-$ data are not normally distributed \\
\hline \multirow{2}{*}{ Fisher-Snedecor } & $\begin{array}{l}\mathrm{H}_{0} \text { - there are no significant differences between average value values of variance for the } \\
\text { compared methods of the surface treatment }\end{array}$ \\
\hline & $\begin{array}{l}\mathrm{H}_{1}-\text { there are significant differences between average value values of variance for the compared } \\
\text { methods of the surface treatment }\end{array}$ \\
\hline \multirow{2}{*}{ t-Student } & $\begin{array}{l}\mathrm{H}_{0}-\text { there are no significant differences between average values for the compared methods of } \\
\text { the surface treatment }\end{array}$ \\
\hline & $\begin{array}{l}\mathrm{H}_{1} \text { - there are significant differences between average values for the compared methods of the } \\
\text { surface treatment }\end{array}$ \\
\hline \multirow{2}{*}{ Cochran-Cox } & $\begin{array}{l}\mathrm{H}_{0} \text { - there are no significant differences between average values for the compared methods of } \\
\text { the surface treatment }\end{array}$ \\
\hline & $\begin{array}{l}\mathrm{H}_{1} \text { - there are significant differences between average values for the compared methods of the } \\
\text { surface treatment }\end{array}$ \\
\hline
\end{tabular}

Table 3. Parameters of descriptive statistics and Shapiro-Wilk test results

\begin{tabular}{|c|c|c|c|c|c|c|c|c|c|}
\hline $\begin{array}{c}\text { Method of surface } \\
\text { treatment }\end{array}$ & Mdn & Min. & Max. & Var. & SD & Skewness & Kurtosis & W & $p$ \\
\hline $\mathrm{P} 120_{\text {I }}$ & 7.10 & 6.38 & 9.36 & 1.24 & 1.11 & 0.61 & -1.25 & 0.91 & 0.39 \\
\hline $\mathrm{P} 800_{\text {I }}$ & 9.97 & 9.26 & 10.8 & 0.27 & 0.52 & 0.76 & 0.61 & 0.93 & 0.58 \\
\hline $\mathrm{D}_{\text {I }}$ & 6.68 & 5.72 & 7.86 & 0.59 & 0.77 & 0.09 & -0.60 & 0.93 & 0.53 \\
\hline $\mathrm{P} 120_{\|}$ & 0.50 & 0.30 & 0.88 & 0.05 & 0.23 & 1.23 & 1.66 & 0.90 & 0.38 \\
\hline $\mathrm{P} 800_{\|}$ & 0.38 & 0.30 & 0.50 & 0.01 & 0.07 & 0.45 & -0.84 & 0.97 & 0.86 \\
\hline $\mathrm{D}_{\|}$ & 0.36 & 0.18 & 0.46 & 0.02 & 0.13 & -0.20 & -2.78 & 0.82 & 0.09 \\
\hline $\mathrm{P} 120_{\| I I}$ & 0.85 & 0.59 & 1.98 & 0.34 & 0.58 & 0.38 & -2.27 & 0.85 & 0.11 \\
\hline $\mathrm{P} 800_{\| I}$ & 0.78 & 0.66 & 1.00 & 0.02 & 0.13 & 0.57 & -0.85 & 0.92 & 0.48 \\
\hline $\mathrm{D}_{\text {III }}$ & 1.18 & 0.73 & 1.98 & 0.16 & 0.40 & 0.82 & 0.46 & 0.96 & 0.77 \\
\hline
\end{tabular}



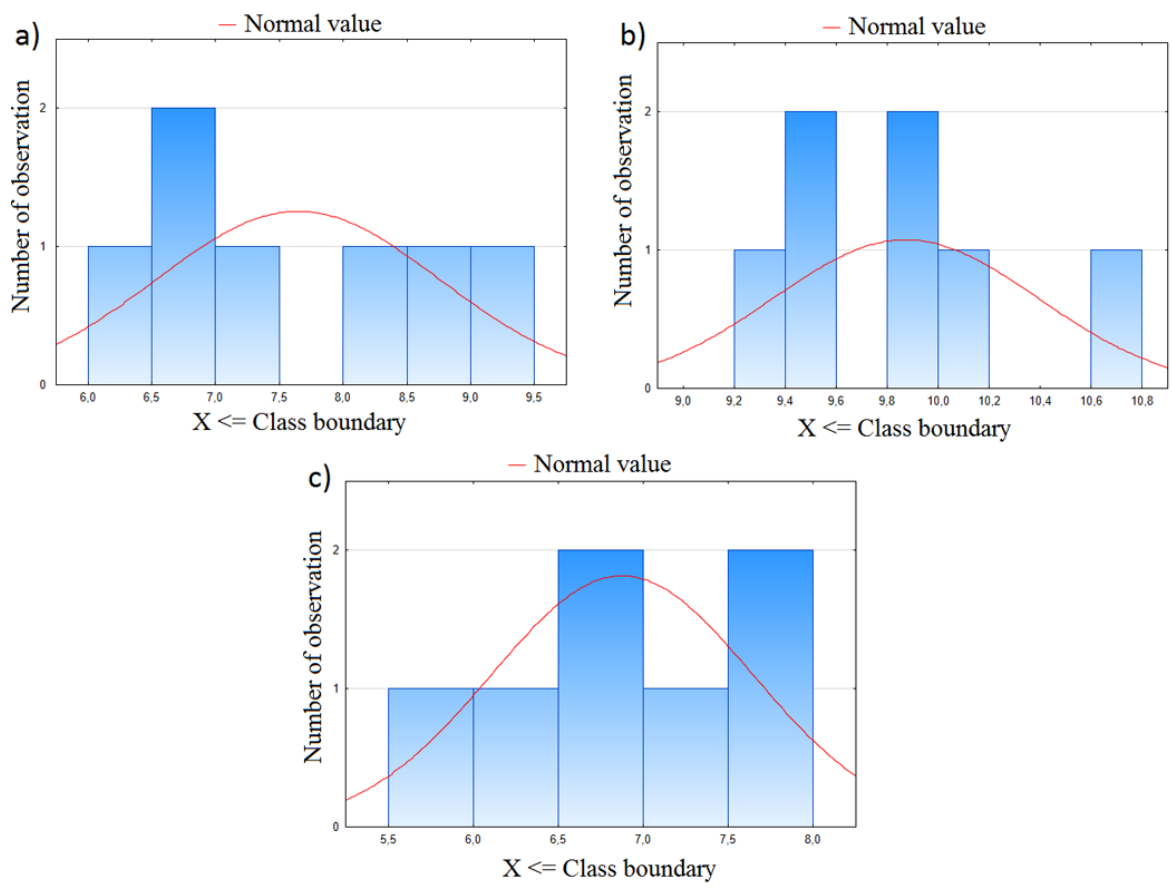

Fig. 5. Histograms of normality - Variant I: a) $P 120_{I}$, b) $P 800_{I}$, c) $D_{I}$
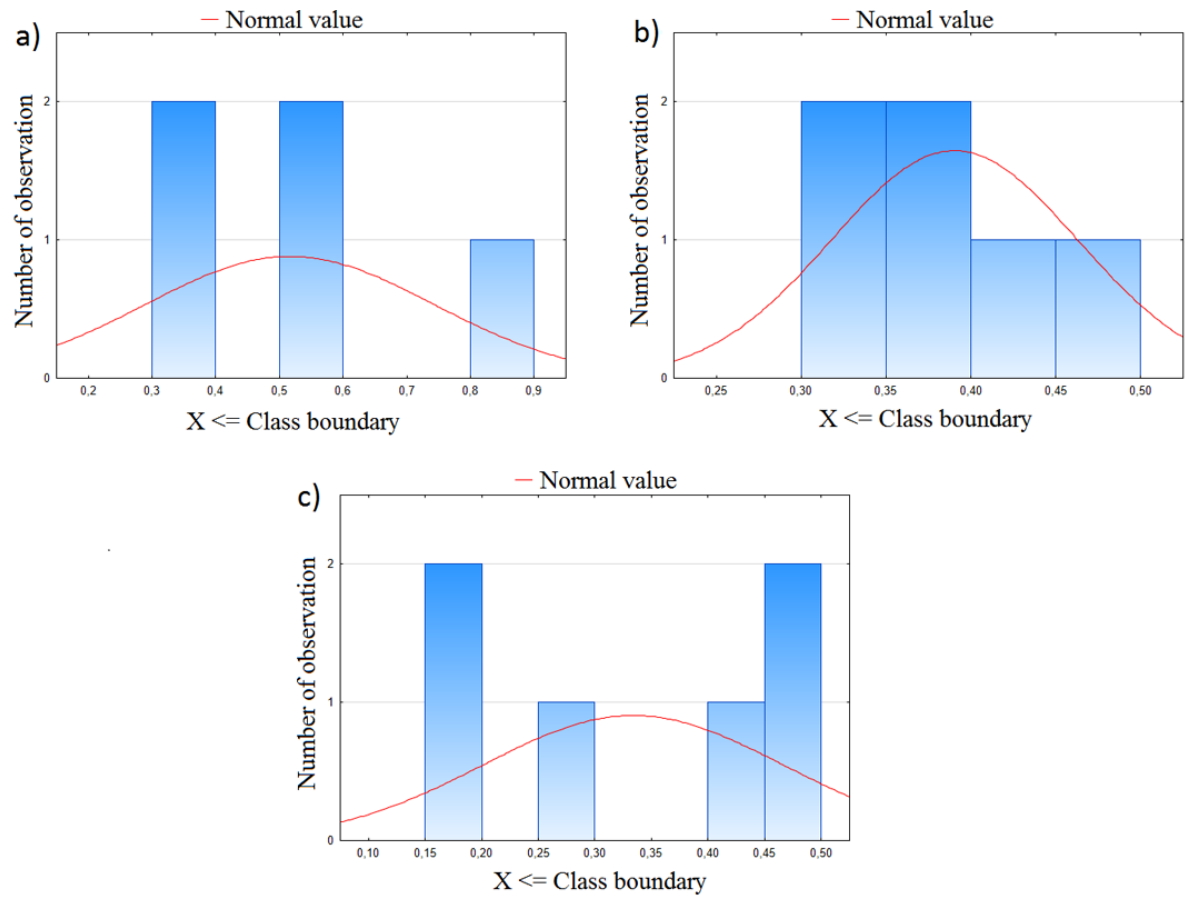

Fig. 6. Histograms of normality - Variant II: a) $\mathrm{P} 120_{\text {II }}$, b) $\mathrm{P} 800_{\text {II }}$, c) $\mathrm{D}_{\text {II }}$

descriptive statistics were calculated and the statistical analysis of the strength results was carried out. The surface roughness tests were also conducted prior to the bonding process.

The surface roughness tests allowed determining that the lowest mean values of the roughness parameters occurred for the treatment with the P800 abrasive paper.
On the basis of the conducted experiment, it can be concluded that the method of surface treatment (before mosaic plaster coating) affects the strength of the single-lap adhesive joints. The highest mean values of the shear strength were obtained for the samples prepared with the P800 abrasive paper and degreasing (variant I) as well as the P120 paper and degreasing (variant II). For 

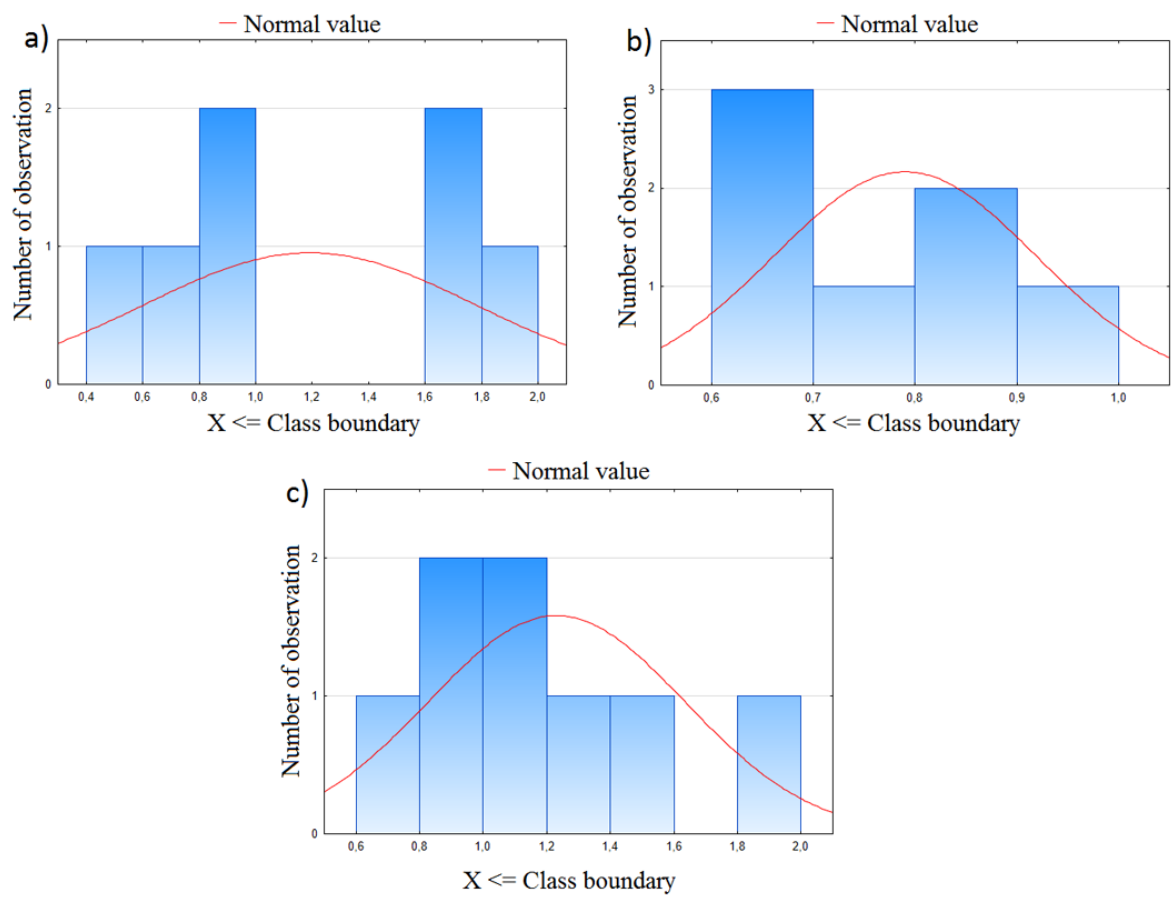

Fig. 7. Histograms of normality - Variant III: a) $\mathrm{P} 120_{\text {III }}$, b) $\mathrm{P} 800_{\text {III }}$ c) $\mathrm{D}_{\text {III }}$

Table 4. Fisher-Snedecor test results

\begin{tabular}{|c|c|c|c|c|c|c|}
\hline Variant & $\begin{array}{l}\text { Compared methods of } \\
\text { the surface treatment }\end{array}$ & $F$ & & $F_{\alpha}$ & Result & Adopted test \\
\hline \multirow{3}{*}{ I } & $\mathrm{P} 120_{1}-\mathrm{P} 800_{1}$ & 4.59 & $>$ & 4.28 & $\begin{array}{l}\text { There are reasons to reject the } \mathrm{H}_{o} \\
\text { hypothesis and accept the } \mathrm{H}_{1} \text { hypothesis }\end{array}$ & Cochran-Cox \\
\hline & $P 120,-D_{1}$ & 2.09 & $<$ & 4.28 & $\begin{array}{l}\text { There are no reasons to reject the } \mathrm{H}_{\circ} \\
\text { hypothesis }\end{array}$ & t-Student \\
\hline & $P 800_{1}-D_{1}$ & 2.19 & $<$ & 4.28 & $\begin{array}{l}\text { There are no reasons to reject the } \mathrm{H}_{\mathrm{o}} \\
\text { hypothesis }\end{array}$ & t-Student \\
\hline \multirow{3}{*}{ II } & $\mathrm{P} 120_{\|}-\mathrm{P} 800_{\|}$ & 9.69 & $>$ & 5.19 & $\begin{array}{l}\text { There are reasons to reject the } \mathrm{H}_{o} \\
\text { hypothesis and accept the } \mathrm{H}_{1} \text { hypothesis }\end{array}$ & Cochran-Cox \\
\hline & $P 120_{\|}-D_{\|}$ & 2.93 & $<$ & 5.19 & $\begin{array}{l}\text { There are no reasons to reject the } \mathrm{H}_{\circ} \\
\text { hypothesis }\end{array}$ & t-Student \\
\hline & $P 800_{\|}-D_{\|}$ & 3.31 & $<$ & 5.05 & $\begin{array}{l}\text { There are no reasons to reject the } \mathrm{H}_{\circ} \\
\text { hypothesis }\end{array}$ & t-Student \\
\hline \multirow{3}{*}{ III } & $\mathrm{P} 120_{1 \mid I}-\mathrm{P} 800_{1 \mid I}$ & 20.62 & $>$ & 4.28 & $\begin{array}{l}\text { There are reasons to reject the } \mathrm{H}_{o} \\
\text { hypothesis and accept the } \mathrm{H}_{1} \text { hypothesis }\end{array}$ & Cochran-Cox \\
\hline & $P 120_{|| I}-D_{\text {III }}$ & 2.11 & $<$ & 3.87 & $\begin{array}{l}\text { There are no reasons to reject the } \mathrm{H}_{\circ} \\
\text { hypothesis }\end{array}$ & t-Student \\
\hline & $P 800_{111}-D_{111}$ & 9.78 & $>$ & 3.87 & $\begin{array}{l}\text { There are reasons to reject the } \mathrm{H}_{o} \\
\text { hypothesis and accept the } \mathrm{H}_{1} \text { hypothesis }\end{array}$ & Cochran-Cox \\
\hline
\end{tabular}

Table 5. t-Student test results

\begin{tabular}{|c|c|c|c|c|c|}
\hline Variant & $\begin{array}{l}\text { Compared methods of } \\
\text { the surface treatment }\end{array}$ & $t$ & & $t_{\alpha}$ & Result \\
\hline \multirow[b]{2}{*}{1} & $P 120,-D_{1}$ & 1.51 & $<$ & 2.18 & There are no reasons to reject the $\mathrm{H}_{\mathrm{o}}$ hypothesis \\
\hline & $P 800_{1}-D_{1}$ & 8.55 & $>$ & 2.18 & $\begin{array}{l}\text { There are reasons to reject the } \mathrm{H}_{0} \text { hypothesis and accept } \\
\text { the } \mathrm{H}_{1} \text { hypothesis }\end{array}$ \\
\hline \multirow{2}{*}{ II } & $P 120_{\|}-D_{\|}$ & 1.67 & $<$ & 2.26 & There are no reasons to reject the $\mathrm{H}_{\mathrm{o}}$ hypothesis \\
\hline & $P 800_{\|}-D_{\|}$ & 0.92 & $<$ & 2.23 & There are no reasons to reject the $\mathrm{H}_{\mathrm{o}}$ hypothesis \\
\hline III & $P 120_{I I I}-D_{I I I}$ & -0.16 & $<$ & 2.16 & There are no reasons to reject the $\mathrm{H}_{\mathrm{o}}$ hypothesis \\
\hline
\end{tabular}


Table 6. Cochran-Cox test results

\begin{tabular}{|c|c|c|c|c|c|}
\hline Variant & $\begin{array}{l}\text { Compared methods of } \\
\text { the surface treatment }\end{array}$ & $C$ & & $C_{\alpha}$ & Result \\
\hline I & $\mathrm{P} 120,-\mathrm{P} 800$, & 444 & $>$ & 2.45 & $\begin{array}{l}\text { There are reasons to reject the } \mathrm{H}_{\mathrm{o}} \text { hypothesis and accept the } \mathrm{H}_{1} \\
\text { hypothesis }\end{array}$ \\
\hline II & $\mathrm{P} 120_{\|}-\mathrm{P} 800_{\|}$ & 1.10 & $<$ & 2.77 & There are no reasons to reject the $\mathrm{H}_{0}$ hypothesis \\
\hline \multirow[b]{2}{*}{ III } & $\mathrm{P} 120_{I I I}-\mathrm{P} 800_{I I I}$ & 1.64 & $<$ & 2.45 & There are no reasons to reject the $\mathrm{H}_{\mathrm{o}}$ hypothesis \\
\hline & $P 120_{I I I}-D_{I I I}$ & 2.75 & $>$ & 2.37 & $\begin{array}{l}\text { There are reasons to reject the } \mathrm{H}_{0} \text { hypothesis and accept the } \mathrm{H}_{1} \\
\text { hypothesis }\end{array}$ \\
\hline
\end{tabular}

both variants, the lowest average strength value was observed for samples prepared by using only a degreaser.

The variant of the sample adhesive joints also affects the strength of the constituted adhesive joint. This is due to the fact that for variant III, the highest shear strength occurred for the degreasing of the surface of samples and the lowest for processing with the $\mathrm{P} 800$ abrasive paper with degreasing. While comparing the obtained results, it can be noticed that there are differences between the average strength values for variant I and variant II and III. Hence, it can be concluded that applying a layer of mosaic plaster on one (variant III) or two joined surfaces (variant II) causes a reduction in the average values of the shear strength of the single-lap adhesive joints.

\section{REFERENCES}

1. Mittal, K.L. and American Chemical Society: Adhesive Joints: Formation, Characteristics, and Testing. Plenum Press, 1984.

2. Rudawska, A., Kuczmaszewski, J.: Klejenie blach ocynkowanych. Wyd. Uczelniane PL, Lublin, 2005.

3. Arenas, M.J., Alia, C., Julián, J.N.J., Ocaña, R., González, C.: Considerations for the industrial application of structural adhesive joints in the aluminium-composite material bonding. Composites Part B: Engineering, 44(1), 2013, 417-423.

4. $\mathrm{Xu}, \mathrm{W} ., \mathrm{Wei}, \mathrm{Y} . \mathrm{G}$. : Strength and interface failure mechanism of adhesive joints. International Journal of Adhesion and Adhesives, 34, 2012, 80-92.

5. Boutar, Y., Naïmi, S., Mezlini, S., Sik Ali, M.B.: Effect of surface treatment on the shear strength of aluminium adhesive single-lap joints for automotive applications. International Journal of Adhesion and Adhesives, 67, 2016, 38-43.

6. Díaz-Benito, B., Velasco, F., Pantoja, M.: Mechanical properties of polyester films painted after silanization of 6063 aluminium alloy with different pretreatment conditions. Progress in Organic Coatings, 70(4), 2011, 287-292.
7. Borsellino, C., Di Bella, G., Ruisi, V.F.: Adhesive joining of aluminium AA6082: The effects of resin and surface treatment. International Journal of Adhesion and Adhesives, 29(1), 2009, 36-44.

8. da Silva, L.F.M., Carbas, R.J.C., Critchlow, G.W., Figueiredo, M.A.V., Brown, K.: Effect of material, geometry, surface treatment and environment on the shear strength of single lap joints. International Journal of Adhesion and Adhesives, 29(6), 2009, 621-632.

9. Prolongo, S.G., Urena, A.: Effect of surface pre-treatment on the adhesive strength of epoxyaluminium joints. International Journal of Adhesion and Adhesives, 29(1), 2009, 23-31.

10. Zielecki, W., Pawlus, P., Perłowski, R., Dzierwa, A.: Surface topography effect on strength of lap adhesive joints after mechanical pre-treatment. Archives of Civil and Mechanical Engineering, 13(2), 2013, 175-185.

11. Satheeshkumar, V., Ganesh Narayanan, R.: Prediction of formability of adhesive bonded steel sheets and experimental validation. In: Archives of Civil and Mechanical Engineering, 15(1), 2015, 30-41.

12. Ebnesajjad, S.: Handbook of Adhesives and Surface Preparation - Technology Applications and Manufactoring. Elsevier, 2011.

13. Spaggiari, A.: Effect of Mechanical Surface Treatment on the Static Strength of Adhesive Lap Joints. International Journal of Adhesion and Adhesives, 89(9), 2013, 677-696.

14. Ebnesajjad, S., Ebnesajjad, C.: Surface Treatment of Materials for Adhesive Bonding, 2 nd edition. Inc. Norwich, William Andrew, NY, 2013.

15. Saleema, N., Sarkar, D.K., Paynter, R.W., Gallant, D., Eskandarian, M.: A simple surface treatment and characterization of AA 6061 aluminum alloy surface for adhesive bonding applications. Applied Surface Science, 261(15), 2012, 742-748.

16. Rudawska, A.: Selected aspects of the effect of mechanical treatment on surface roughness and adhesive joint strength of steel sheets. International Journal of Adhesion and Adhesives, 50, 2014, 235-243.

17. Giesteira, F.A.G., Marques, E.A.S., Carbas, R.J.C., da Silva, L.F.M.: Prediction of Joint Strength and Effect of the Surface Treatment on the Single Overlap 
Adhesive Joints. U.Porto Journal of Engineering, 3(3), 2017, 1-16.

18. Uehara, K., Sakurai, M.: Bonding strength of adhesives and surfaces roughness of joined parts. Journal of Materials Processing Technology, 127(2), 2002, 178-181.

19. Rudawska A.: Surface treatment in Bonding Technology. Academic Press, 2019.

20. PN-EN 1465:2009 - Adhesives - Determination of tensile lap-shear strength of bonded assemblies.
21. PN-EN ISO 4288:2011 - Geometrical product specifications (GPS) - Surface texture: Profile method - Terms, definitions and surface texture parameters.

22. Rozali, N.M., Wah, Y.B.: Power comparisons of Shapiro-Wilk, Kolmogorov-Smirnov, Lilliefors and Anderson-Darling tests. Journal of Statistical Modeling and Analytics, 2(1), 2011, 21-33.

23. Hilbe, J.M., STATISTICA 7: An Overview. The American Statistician, 61(1), 2007, 91-94. 